\title{
Simulating and Building an Appliance Clustering Fuzzified SVC for Single Phase System
}

\author{
Osama Ahmed, Abdul Wali Abdul Ali" \\ Centre for Electric Energy and Automation (CEEA) Faculty of Engineering, Multimedia University, Cyberjaya, Malaysia \\ *Corresponding Author: walikdr17@gmail.com, Tel: 601-114320521
}

\begin{abstract}
A power system suffers from losses that can cause tragic consequences. Reactive power presence in the power system increases system losses delivered power quality and distorted the voltage. As a result, many studies are concerned with reactive power compensation. The necessity of balancing resistive power generation and absorption throughout a power system gave birth to many devices used for reactive power compensation. Static Var Compensators are hunt devices used for the generation or absorption of reactive power as desired. SVCs provide fast and smooth compensation and power factor correction. In this paper, a Fuzzified Static Var Compensator consists of Thyristor Controlled Reactor (TCR) branch and Thyristor Switched Capacitors branches for reactive power compensation and power factor correction at the load side is presented. The system is simulated using Simulink using a group of blocks and equations for measuring power factor, determining the weightage by which the power factor is improved, determining the firing angle of the TCR branch, and capacitor configuration of TSC branches. Furthermore, static and dynamic loads are used to test the system's capability in providing fast response and compensation. The simulation results illustrated the proposed system's ability and responsiveness to compensate for the reactive power and correct the power factor. It also highlighted the proportional relation between reactive power presence and the increased cost of electricity bills. This paper only focuses on the simulation part of this project.
\end{abstract}

Keywords: Fuzzification, SVC, TCR, TRIAC, Power factor, Reactive Power, Power loss, Harmonic

(C) 2021 Penerbit UTM Press. All rights reserved

Article History: received 8 October 2020; accepted 22 April 2021; published 30 April 2021.

\section{INTRODUCTION}

The expansion of population and cities has led to more electric power demand; therefore, the increase in demand resulted in expanding power grids and transmission systems. Consequently, this significant expansion was associated with performance deficiencies and other challenges primarily concerned with utility grids [1-3]. Therefore, many research areas were opened to mitigate all the challenges, deliver high quality, and satisfy energy consumers. As a result, more focus was put into developing new schemes that can help in stabilizing the power system, one of these developed devices was the FACT device named as Static Var Compensators (SVC), which can be connected in shunt or series with the power system and compensate the reactive power. Furthermore, proper monitoring of the power system was desired as it can be helpful for power quality improvement and future planning and expansions; therefore, the concept of smart meters and smart grids were introduced. This thesis contains relevant details concerning the smart meter used for power monitoring and power factor correction for home appliances [4].

When the power quality topic is touched, it is always associated with Smart Grids (SGs), Advanced Metering Infrastructure (AMI), Smart Meters, and Reactive Power Compensator (RPCs) [5-12]. A Smart Grid can be defined as an electricity network that can integrate its connected equipment and users' activities and behaviours to achieve an economical, efficient, sustainable, secure, and safe electric power supply [1-2]. AMI is an integrated system that uses smart meters, communication devices, data management systems, and associated software and hardware. The spread of AMI usage introduced a big data challenge due to the high volume of data, velocity, variety, or all three. A smart meter can be defined as an electricity measuring technique that utilizes real-time sensors to measure electric power, monitor power quality, and notify for power outages and power theft and facilitate electric billing [1]. Lastly, the development of power electronics gave birth FACTs devices to improve voltage stability and reactive power compensation [3].

Most of the available SVC research studies, if not all, are focusing on compensation at week buses of transmission lines using Fixed Capacitor-TCRs. The approaches described in the following section are either RPC or Smart meters or Smart Meter using Fixed Capacitor (FC) for power factor correction. The proposed method of this research is a combination of ZigBee-based Smart meter and SVC that consists of TCR and four TSCs in order to fulfill power quality requirements. However, in contrast to the reviewed approaches, the proposed model deals with compensation at the load side and not at the week buses of transmission lines. Therefore, the compensation is done at the root of the 
problem to improve power quality, improve voltage regulation, and reduce power cost [13-17].

\section{DETAILS OF THE DESIGN}

This project consisted of a simulation model and a hardware implementation model.

\subsection{SVC Simulation model}

The simulation model comprises three parts; simulated circuit, measurement, monitoring unit, and calculation and control unit. The circuit was built using the MatlabSimulink Simscape Power Systems library, as shown in Figure 1. The main components of the circuit are; powergui block for running the simulation, AC Source, Series RL branches that are used as source impedance and switching frequency filters, respectively, enable blocks which are used for controlling the TSC branches, Thyristors and a series RL load branch model as the system load.

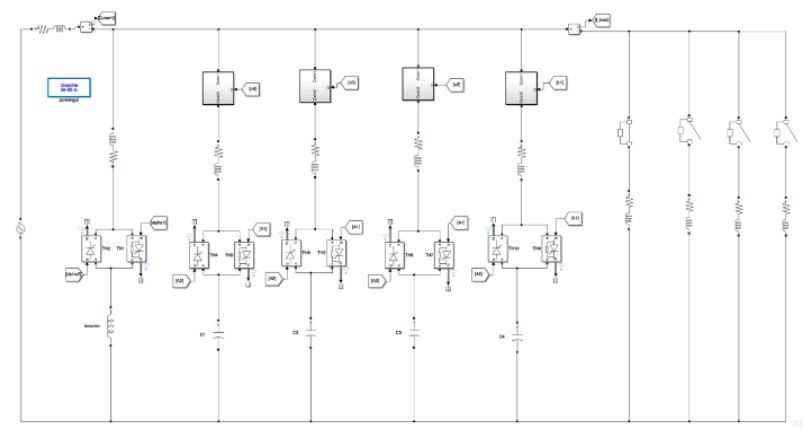

Figure 1. SVC Circuit Model 1

\subsection{Calculations and Control Unit}

The unit consisted of the calculations blocks used to compute the desired power factor, capacitance, and firing angle for thyristor and control pulses blocks for TCS and TCR. Simulink Matlab functions (FCN) were used for inserting the computation equations. A two-input singleoutput Fuzzy Logic controller (FLC) was used to compute the weightage by which the power factor was improved. The following equations were used to calculate the desired power factor, capacitor configuration, and firing angle [14-15].

$$
\begin{aligned}
& P F_{\text {desired }}=\left(\left(1-P F_{\text {old }}\right) * W\right)+P F_{\text {old }} \\
& M_{F}=\tan \left(\cos ^{-1}(P F)\right)-\tan \left(\cos ^{-1}\left(P_{-} \text {desired }\right)\right) \\
& P=V_{r m s} * I_{r m s} * P F_{\text {old }} \\
& Q_{c}=P * M_{F} \\
& \mathrm{X}_{\mathrm{c}}=\mathrm{V}_{r m s}^{2} / Q_{C} \\
& \mathrm{C}=\frac{1}{2 \pi * f * X_{C}} \\
& Q_{L}+\left(20 \% * Q_{L}\right)=V_{r m s}^{2} / Q_{C}
\end{aligned}
$$

$$
\begin{aligned}
& X_{L(T C R)}=\frac{V_{r m s}^{2}}{Q_{L}} \\
& \frac{1}{X_{L(T C R)}}=\frac{(2(\pi-\alpha)-\sin (2(-\alpha))}{\pi X_{L}}
\end{aligned}
$$

where:

$\mathrm{PF}_{\text {old }}$ is the power factor to be corrected.

$\mathrm{PF}_{\text {desired }}$ is the improved power factor.

$\mathrm{M}_{\mathrm{F}}$ is the Multiplication factor to find the required compensation reactive power.

$\mathrm{Q}_{\mathrm{C}}$ is the required reactive power to improve the power factor (VAR).

$\mathrm{X}_{\mathrm{C}=}$ Capacitive reactance $(\Omega)$

$\mathrm{Q}_{\mathrm{L}}$ is the required inductive reactive power for firing angle computation.

$\mathrm{X}_{\mathrm{L}}=$ Inductive reactance $(\mathrm{L}=10 \mathrm{mH}) \& \mathrm{X}_{\mathrm{L}(\mathrm{TCR})}=\mathrm{TCR}$ Inductive reactance $(\Omega)$

$\mathrm{P}=$ Real Power (Watt)

$\mathrm{W}=$ Correction Weightage

$\alpha=$ Firing angle (radian)

\subsection{Determination of Correction Weightage, $W$ using FLC}

The weightage was determined by the use of a FLC that took appliance Type and Current as inputs.

Table 1. Fuzzy Controller Rules

\begin{tabular}{|c|c|c|c|c|c|c|c|c|}
\hline \multirow{1}{*}{} & \multicolumn{7}{|c|}{ Appliance } \\
\cline { 2 - 9 } & & NL & NM & NS & Z & PS & PM & PL \\
\hline \multirow{6}{*}{ Current } & NL & NL & NL & NL & NL & NM & NS & Z \\
\cline { 2 - 9 } & NM & NL & NL & NL & NM & NS & Z & PS \\
\cline { 2 - 9 } & NS & NL & NL & NM & NS & Z & PS & PM \\
\cline { 2 - 9 } & Z & NL & NM & NS & Z & PS & PM & PL \\
\cline { 2 - 9 } & PS & NM & NS & Z & PS & PM & PL & PL \\
\cline { 2 - 9 } & PM & NS & Z & PS & PM & PL & PL & PL \\
\cline { 2 - 9 } & PL & Z & PS & PM & PL & PL & PL & PL \\
\hline
\end{tabular}

\subsection{Appliance Cluster}

Appliance clustering helps group the appliances based on their function and usage; the cluster is estimated based on priorities. Some appliances are continuously used, and they require fast and high correction while others that have less operation time require less correction of do not require correction. Table 2 shows the estimated cluster of each appliance based on their usage and operation times.

\subsection{Determination of Capacitor Configuration}

Equation (6) determined the required capacitance to be installed. There was a total of 4 capacitors $0.5 \mathrm{uF}, 1 \mathrm{uF}$, $2 \mathrm{uF}$, and $4 \mathrm{uF}$. The Total computed capacitance $\mathrm{C}$ was then rounded to upper 0.5 by the Ceiling Matlab built-in function. Suppose a block was used to determine the triggering configuration of the capacitors. Table 3 explained the triggering configuration.

\subsection{Determination of Firing Angle $\alpha$}

The firing angle relation with TCR inductance was described by equation (9). The equation was solved using a numerical method called the bisection method. The bisection method divides an interval into many subintervals for root finding, then the subinterval in 
which the root must lie will be selected and processed to determine the root. A Matlab code was written inside. The output $\mathrm{y}$ from Figure 3 was then converted into seconds and then inputted into a programmable pulse generator to generate the corresponding pulses at positive and negative cycles to trigger the TCR Thyristors.

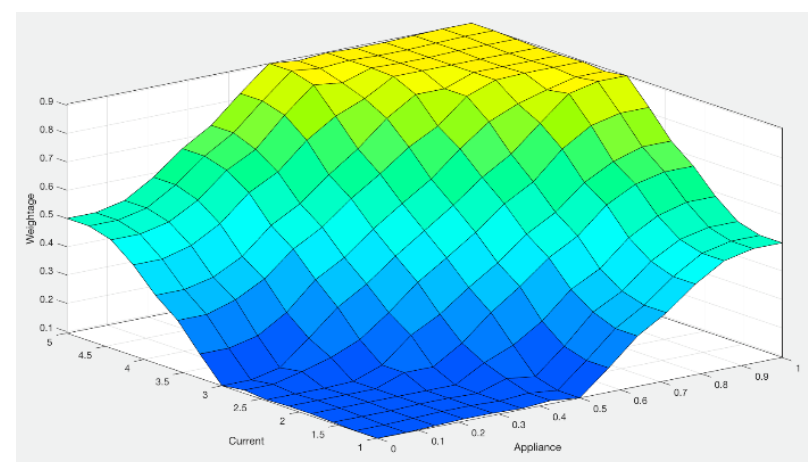

Figure 2. Fuzzy Controller Surface

Table 2. Appliance Cluster Description

\begin{tabular}{|c|c|c|c|c|c|c|c|c|c|}
\hline Appliance & Lights & TV & Kettle & Blender & $\begin{array}{c}\text { Washing } \\
\text { Machine }\end{array}$ & Fan & Refrigerator & $\begin{array}{c}\text { Air } \\
\text { Conditioner }\end{array}$ & $\begin{array}{c}\text { Main } \\
\text { (DP) }\end{array}$ \\
\hline $\begin{array}{c}\text { Appliance } \\
\text { Cluster }\end{array}$ & 0 & 0.1 & 0.25 & 0.50 & 0.80 & 0.90 & 0.95 & 0.99 & 1 \\
\hline
\end{tabular}

Table 1.2: TSC Triggering Configuration

\begin{tabular}{|l|l|c|c|c|c|c|c|c|c|c|c|c|c|c|c|c|c|}
\hline \multicolumn{2}{|c|}{$\begin{array}{c}\text { TSC Trigger in } \\
\text { Hexadecimal }\end{array}$} & 0 & 1 & 2 & 3 & 4 & 5 & 6 & 7 & 8 & 9 & A & B & C & D & E & F \\
\hline Capacitor, $\mathrm{C} 1$ & $4 \mathrm{uF}$ & 0 & 0 & 0 & 0 & 0 & 0 & 0 & 0 & 1 & 1 & 1 & 1 & 1 & 1 & 1 & 1 \\
\hline Capacitor, $\mathrm{C} 2$ & $2 \mathrm{uF}$ & 0 & 0 & 0 & 0 & 1 & 1 & 1 & 1 & 0 & 0 & 0 & 0 & 1 & 1 & 1 & 1 \\
\hline Capacitor, $\mathrm{C} 3$ & $1 \mathrm{uF}$ & 0 & 0 & 1 & 1 & 0 & 0 & 1 & 1 & 0 & 0 & 1 & 1 & 0 & 0 & 1 & 1 \\
\hline Capacitor, $\mathrm{C} 4$ & $\begin{array}{l}0.5 \mathrm{u} \\
\mathrm{F}\end{array}$ & 0 & 1 & 0 & 1 & 0 & 1 & 0 & 1 & 0 & 1 & 0 & 1 & 0 & 1 & 0 & 1 \\
\hline $\begin{array}{l}\text { Total Triggered } \\
\text { Capacitors } \mathrm{C}_{\mathrm{X}}\end{array}$ & $\mathrm{XuF}$ & 0 & 0.5 & 1 & 1.5 & 2 & 2.5 & 3 & 3.5 & 4 & 4.5 & 5 & 5.5 & 6 & 6.5 & 7 & 7.5 \\
\hline
\end{tabular}

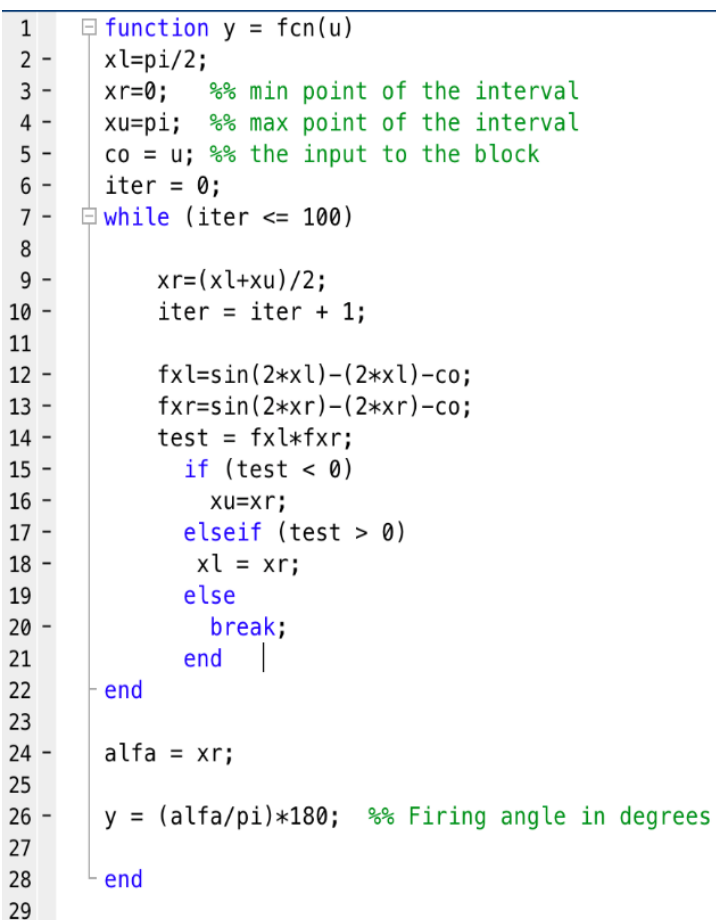

Figure 3. Bisection Method Code for determining Firing angle.

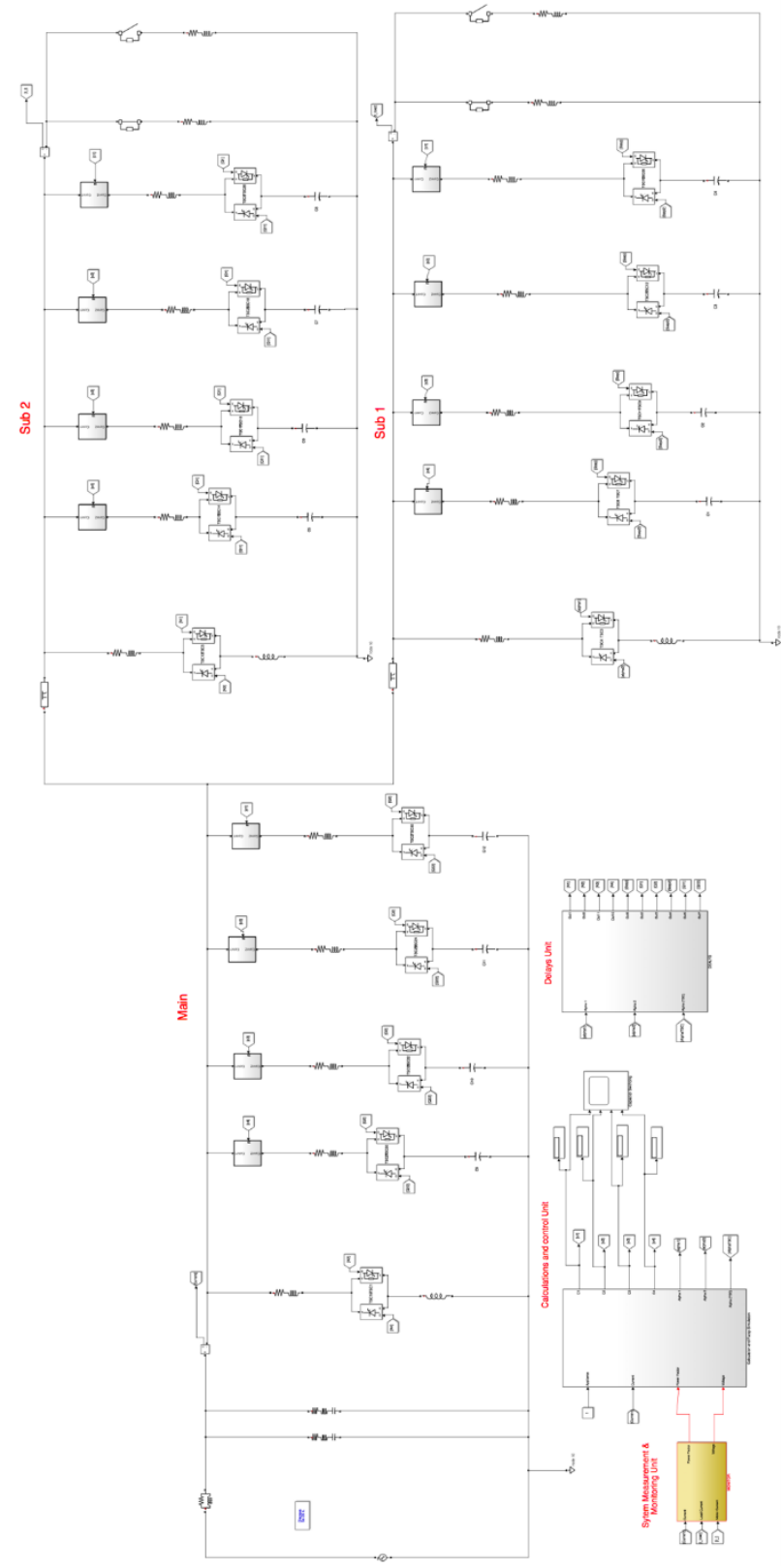

Figure 4. Firing Angle Determination Blocks

\subsection{SVC Circuit Model 2}

The second SVC model, as shown in Figure 5, is an extended version of the previously described model, as the aim here was to control different loads at a different location using pi section model and even distribution of TSCs and TCRs among these loads to achieve power factor correction and reactive power compensation. A new unit named as delay unit was introduced, and it was used to delay the triggering of TCRs and TCSs by a specified amount of time of $0.1 \mathrm{~s}$ and $0.3 \mathrm{~s}$, therefore, staging the correction process. The Fuzzy Logic Controller was also modified, as the range of the current was increased from $1 \mathrm{~A}-5 \mathrm{~A}$ to $1 \mathrm{~A}-30 \mathrm{~A}$ as the current drawn by the new circuit became larger. The new SVC model applied load variation to analyze how fast the SVC control unit can respond to load variation. The load was varied by using breakers and setting these breakers to be 
connected after a specific time causing load variation and disturbance in the system.

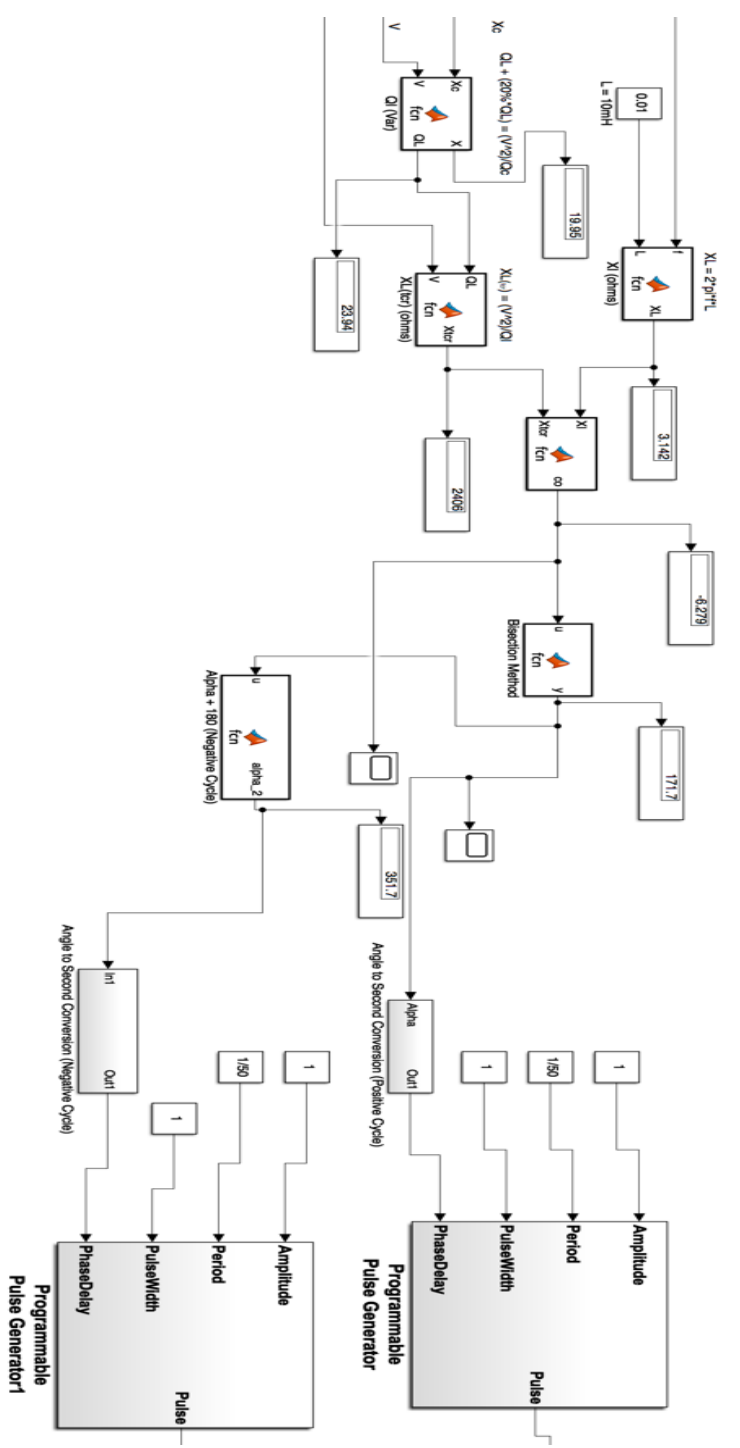

Figure 5. SVC Circuit Model 2

\section{RESULTS PRESENTATION}

This section contained the simulation results and their analysis. The loads were varied at different times during the simulation run as load 1 started with simulation start and removed at $0.2 \mathrm{~s}$, load 2 was connected at $0.2 \mathrm{~s}$ and removed at $0.4 \mathrm{~s}$. Lastly, load 3 was connected at 0.4 to the end of the simulation run time. The variation on current, power factor, real power, and reactive power due to load variation was captured using scope blocks.

This process aims to observe the system response to load variation and its capability to provide efficient and fast compensation of reactive power and power factor improvement. Figures 6 to 11 highlight the simulation results before incorporating the SVC branches, including the power factor, voltage, current, real power, and reactive power of load 1, load 2 load 3 , respectively, as their variation during the simulation run.

\subsection{SVC Model 1, Results}

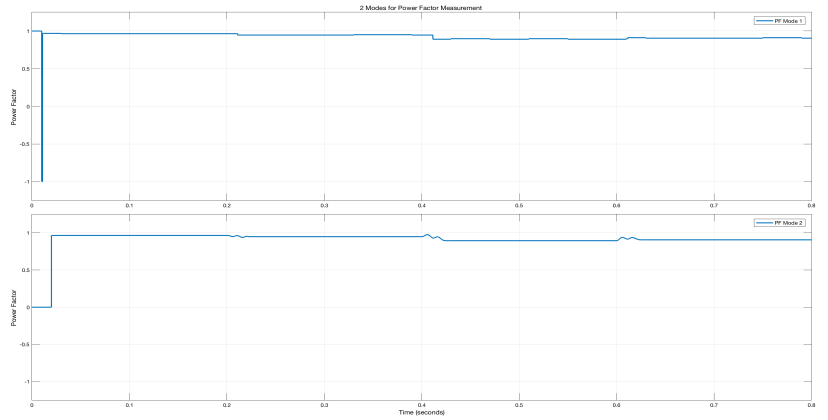

Figure 6. (a) Power Factor Mode 1, (b) Power Factor Mode 2 (without SVC)

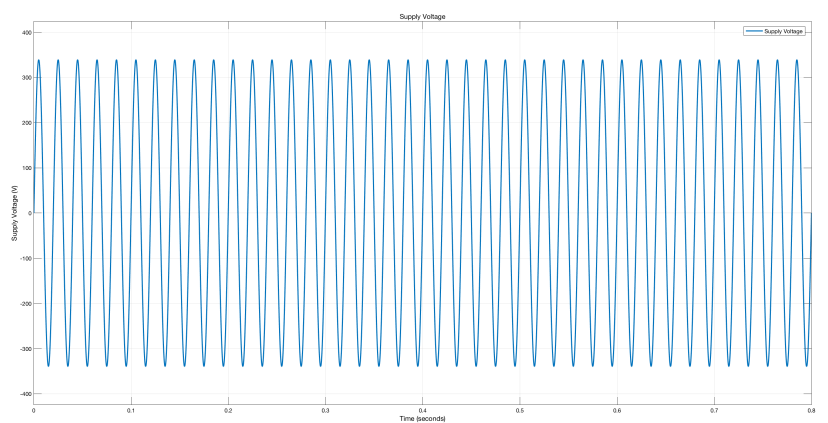

Figure 7. Supply Voltage Waveform (without SVC)

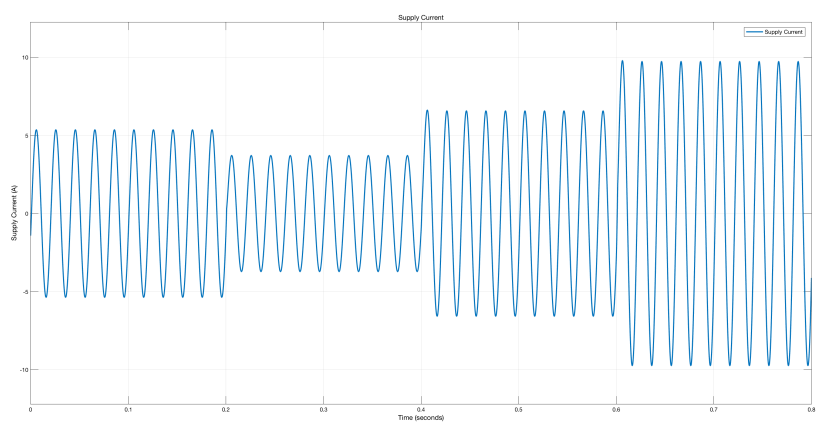

Figure 8. Supply Current Waveform (without SVC)

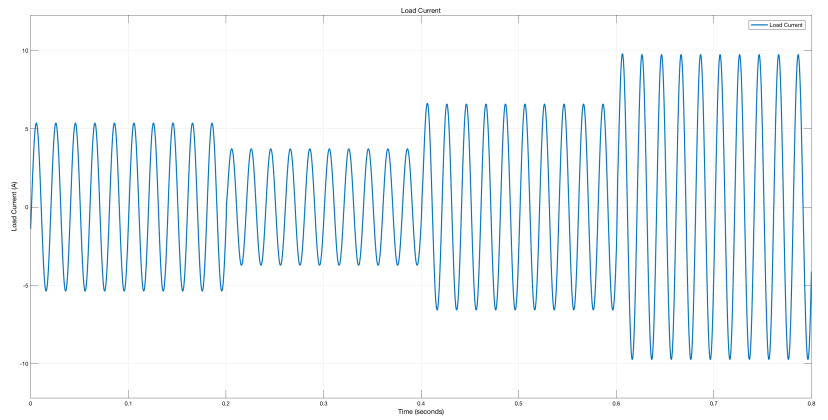

Figure 9. Load Current Waveform (without SVC)

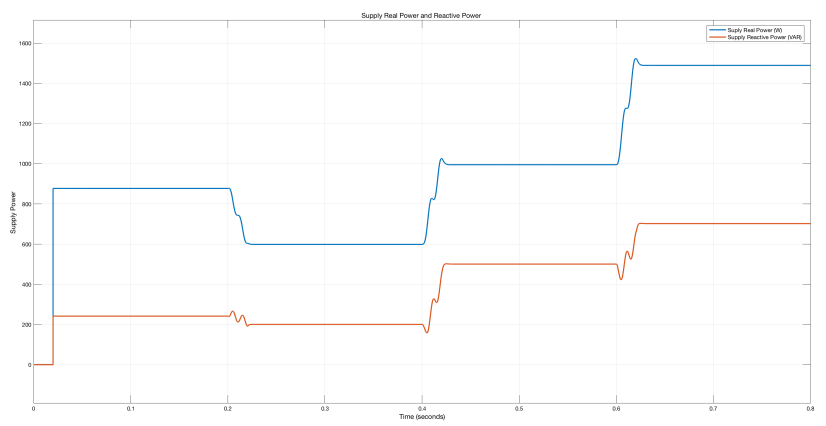

Figure 10. Real and Reactive Power at Supply Side (without SVC) 


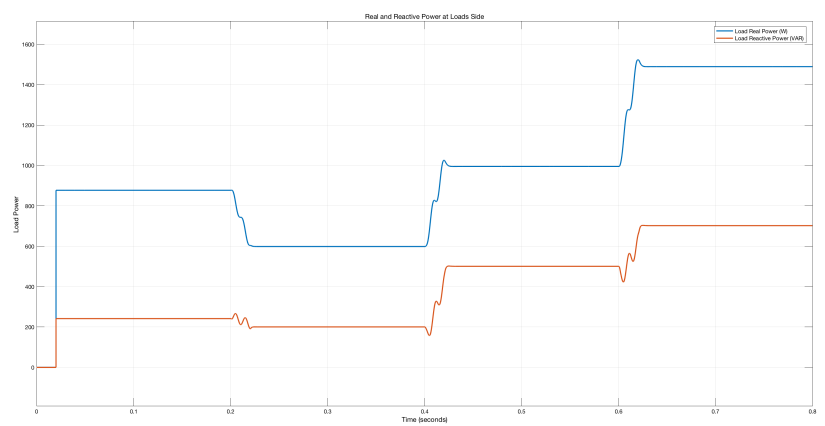

Figure 11. Real and Reactive Power at Loads Side (without SVC)

After adding the SVC to the system, the power factor improved despite load changes, and reactive power was reduced with a small increase in real power. The following graphs highlight the effects of SVC incorporation, capacitor switching, and firing angle variation for reactive power balancing.

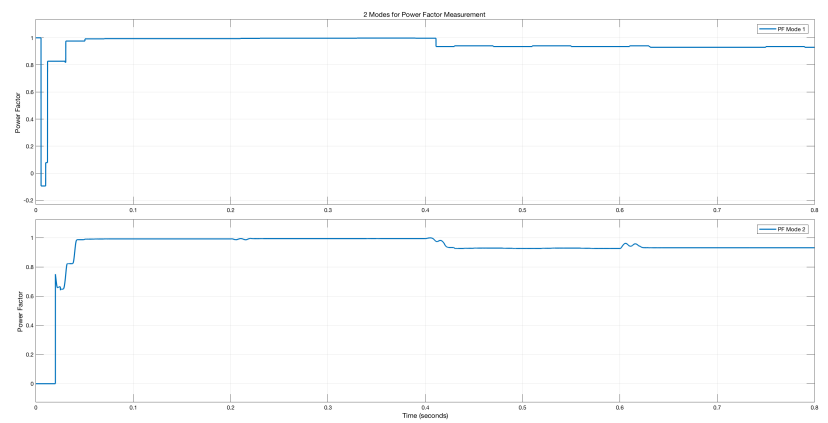

Figure 12. (a) Power Factor Mode 1, (b) Power Factor Mode 2. (with SVC)

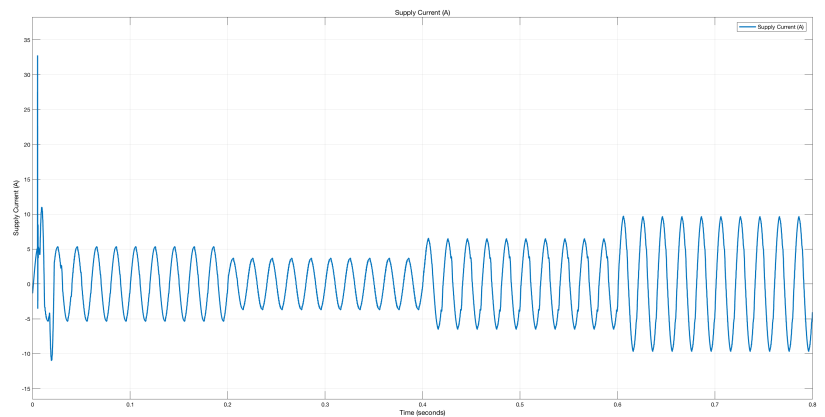

Figure 13. Supply Current Waveform (with SVC)

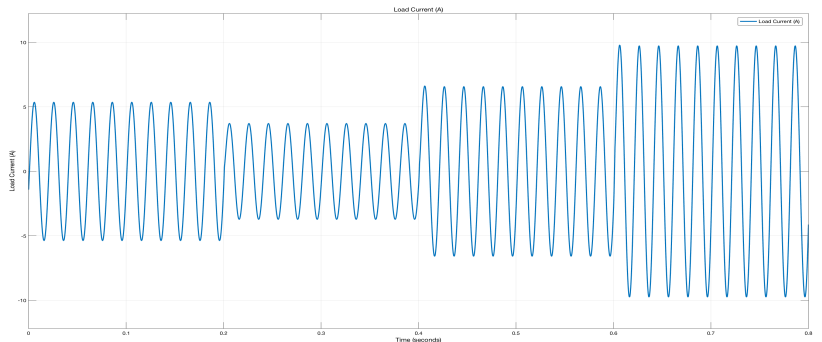

Figure 14. Load Current Waveform (with SVC)

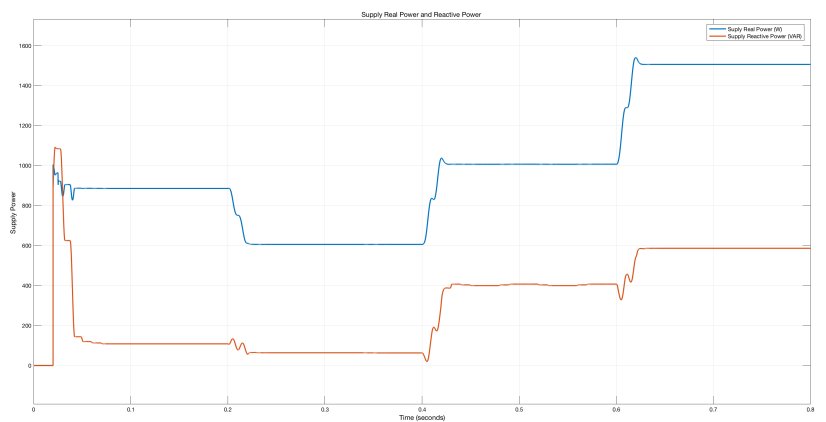

Figure 15. Real Power and Reactive Power at Supply Side (With SVC)

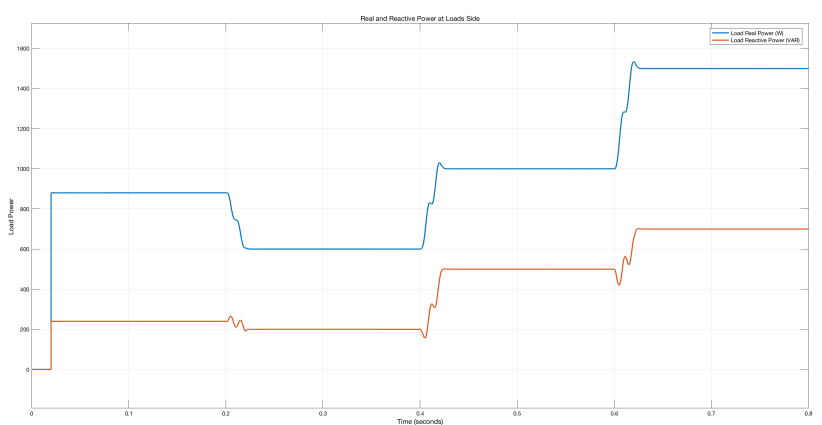

Figure 16. Real Power and Reactive Power at Load Side (With SVC)

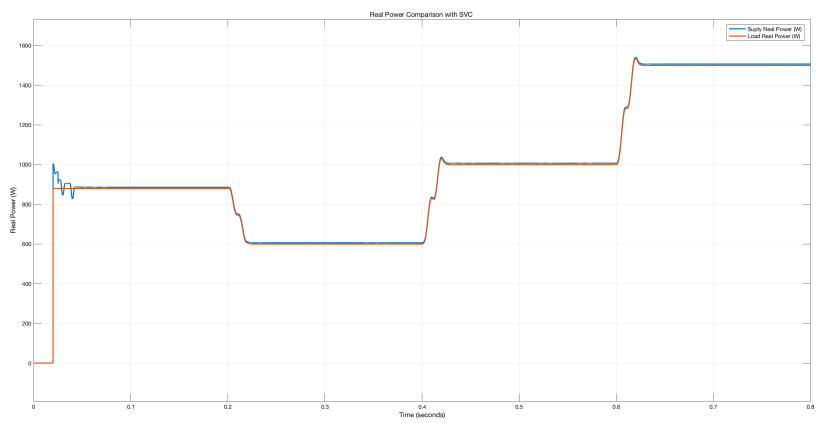

Figure 17. Real Power Comparison (with SVC)

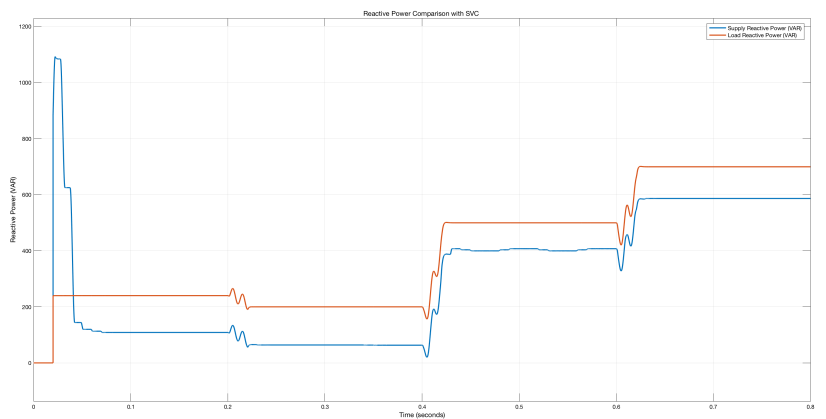

Figure 18. Reactive Power Comparison (with SVC)

Figures 17 to 18 show SVC Model 1 capability to provide a fast and efficient response to load variations and successfully compensate reactive power with little increase in real power. 


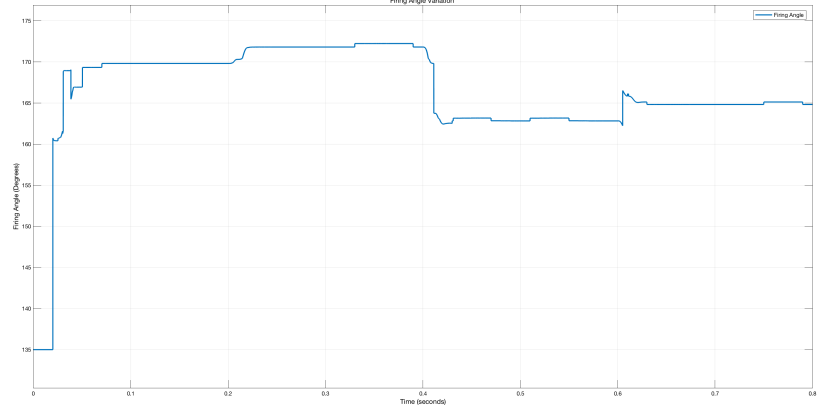

Figure 19. Firing Angle of TCR Variation

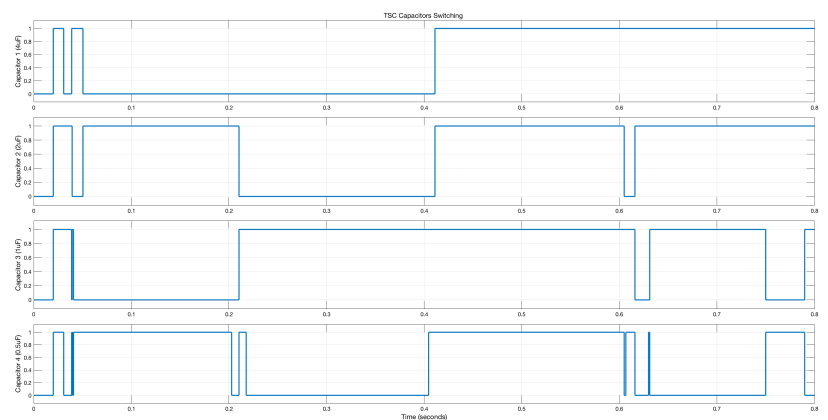

Figure 20. Capacitor Switching during Simulation

\subsubsection{Harmonics Analysis for SVC Model 1}

The supply current waveforms represented in Figures 24 to 25 consist of 40 cycles; using the built-in FFT analysis within the powergui block in Simulink, it was observed that at the beginning of the simulation, the current peak raised to a high, and harmonics presence was relatively high. However, as the system reached its stable state, the harmonic presence was lower than the first cycle. Harmonics presence in the system is related to TCR's interaction with the power system, and they are hard to analyze. Furthermore, load switching is considered a cause of harmonics generation. The following figures highlight harmonics presence before and after SVC incorporation.

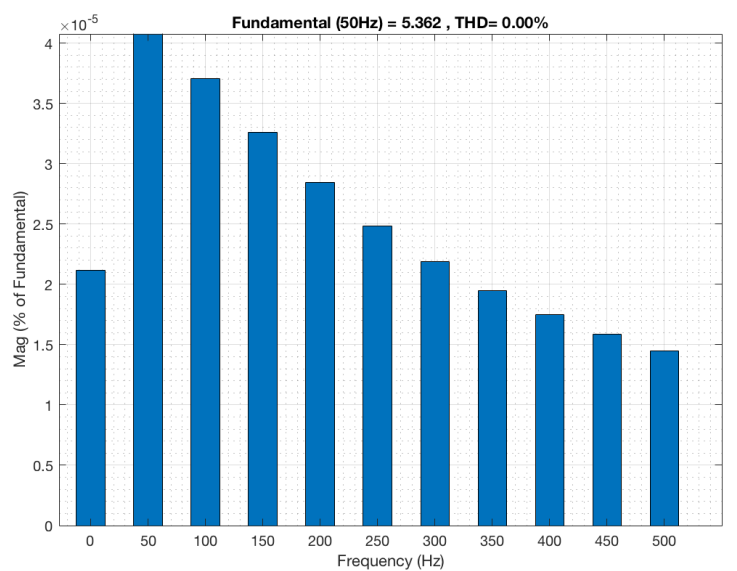

Figure 21. Frequency Spectrum for the first cycle (without SVC)

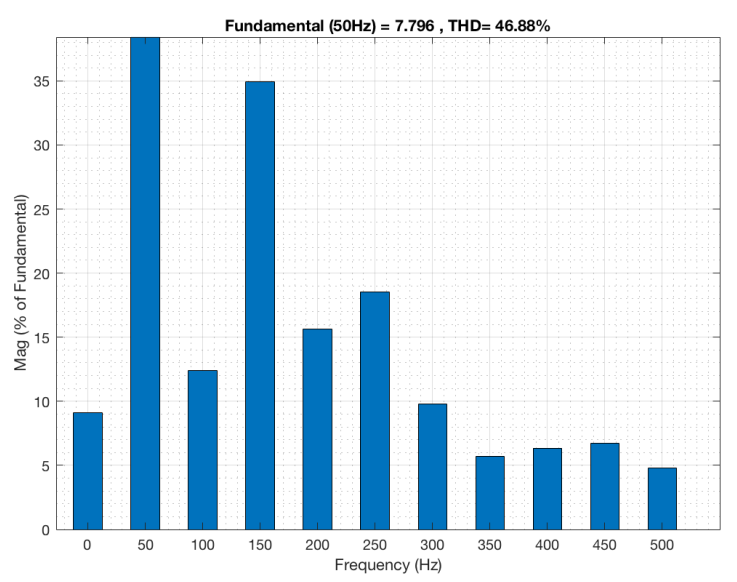

Figure 22. Frequency Spectrum for the first cycle (with SVC)

\subsection{SVC Model 2, Results}

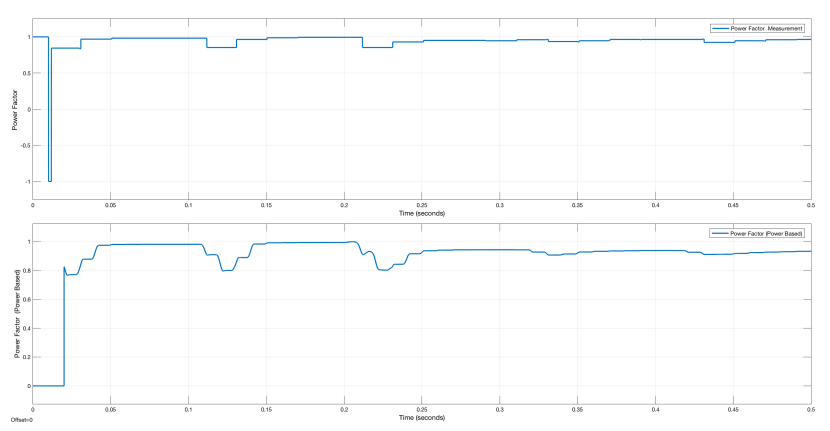

Figure 23. (a) Power Factor Mode 1, (b) Power Factor Mode 2. (with SVC)

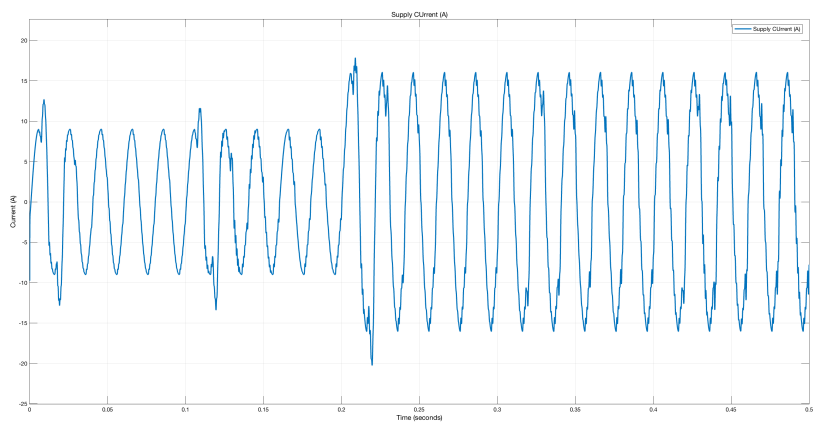

Figure 24. Supply Current Waveform (with SVC)

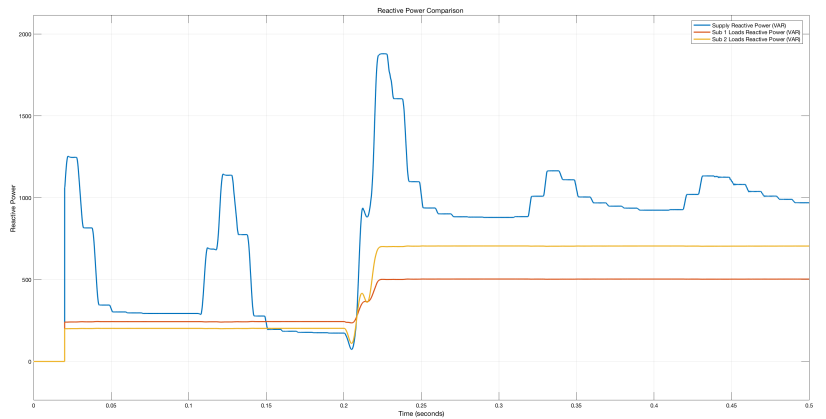

Figure 25 Reactive Power at Load (with SVC) 


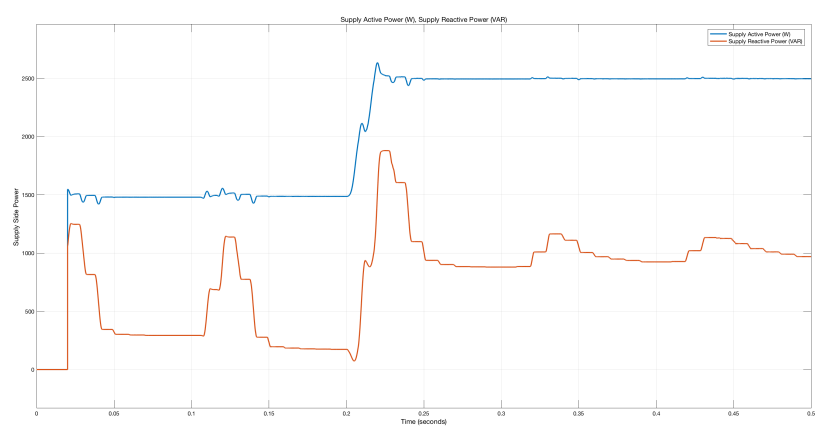

Figure 26: Real and Reactive Power at Supply Side (with SVC)

By looking at Figures 23 to 26, we can see that the reactive power drastically dropped by $80 \%$. SVC Model 1 provided a fast and efficient response to load variations and successfully compensated reactive power while maintaining the same real power.

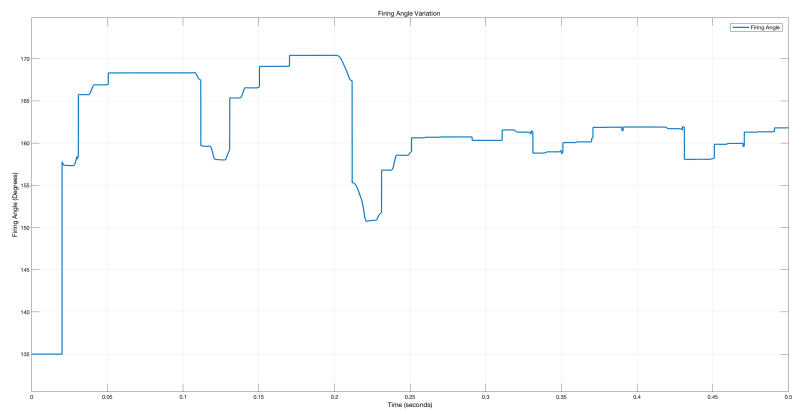

Figure 27: Firing Angle of TCR

\subsubsection{Harmonics Analysis for SVC Model 2}

A rise in the current peak was observed at the beginning of the simulation. But, as the system reached its stable state, the harmonic presence was lower compared to the first cycle. This because SVC model 2 had many switching processes causing current distortion.

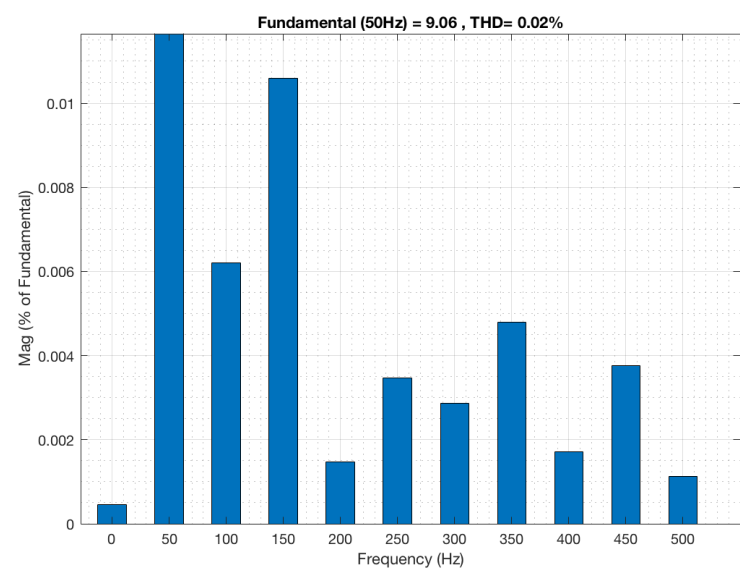

Figure 28: Frequency Spectrum for the First cycle (without SVC)

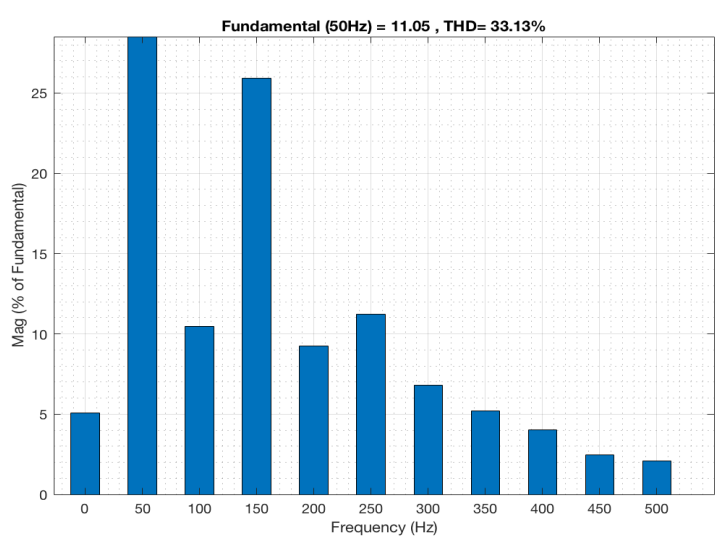

Figure 29: Frequency Spectrum for the First cycle (with SVC)

\section{DISCUSSION OF FINDINGS}

The use of SVC provides power factor correction and reactive power compensation. The reactive power drawn by inductive loads can lead to overloading events in different power system areas, resulting in performance deficiencies and the power system's instability. The reactive power issue may not be of concern to the residential consumer. Most utility companies do not impose penalties on residential or commercial consumers for excessive reactive power. Still, it would be a matter of concern for reducing or minimizing their electric bills. Furthermore, the power factor is defined as the ratio of real power to apparent power, considering this definition. It can be concluded that the power factor is inversely proportional to apparent power. Consequently, any increase in power factors results in a decrease in apparent power, whereas a reduction of the power factor causes an increase in the apparent power [18-23].

It is known that the voltage supplied to residential consumers is equivalent to $240 \mathrm{~V} \mathrm{AC}$, which means the apparent power, $\mathrm{S}$ is directly proportional to the r.m.s current, $\mathrm{I}_{\mathrm{rms}}$, as presented in equation (4.1). Therefore, the decrease in apparent power decreases or reduces the current drawn by the system and vice versa. To put the matter in a nutshell, power factor correction and reactive power compensation improve the power system stability, improve its performance and capacity while minimizing energy cost.

The reviewed literature highlighted the consequences of excessive reactive power presence in the power system and proposed different mitigating these effects. This is because the different sectors and connected consumers of the power system are concerned with efficient and continuous power delivery. The proposed Simulink model can provide power factor correction and compensation of reactive power and keep the power factor close to unity with load variation.

Although the good performance of SVC models, harmonics were present, which is an undesired event. However, the presence did not affect the compensation and Correction process. 


\section{CONCLUSION}

Static Var compensator models were built and modelled in Simulink for reactive power compensation and power factor correction. Dynamic loads were connected and switched and different times and the proposed model was capable of providing fast response to load variations, compensating the reactive power, and correcting the power factor. There was the presence of a harmonic in the system. However, it did not affect the system's operation, and response as compensation and correction processes were successfully carried out despite the load variation and harmonics presence.

The TRIAC power semiconductor's use gave the capability of full control over the voltage and current through the capacitors and inductor in both positive and negative cycles. The firing angle could be varied within the range of full conduction of current to no conduction.

To sum up, Static Var Compensators models were built and tested to analyze the reactive power and do the proper compensation. These models were analyzed based on their operation and performance. Reactive power compensators are essential to achieve high-quality power delivery, which is also associated with high quality and efficient monitoring systems. Therefore, the overall power system performance and stability are improved and would help future expansions of the power system and the increased demand. Furthermore, SVCs usage can be of great advantages for industries, residential consumers, and commercial consumers as SVCs primary goal is achieving high power quality and energy efficiency, which means doing the same work with lesser cost.

\section{ACKNOWLEDGMENT}

This study was supported by the faculty of Engineering, Multimedia University, Malaysia.

\section{REFERENCES}

[1] Geetha and Dr. K. Jamuna, "Smart Metering System”, SA Engineering College, Chennai India.

[2] Yasin Kablaci and Ersan Kablaci, "A Low Cost Smart Metering System Design for Smart Grid Application", presented at the $8^{\text {th }}$ Int. Conf. Electronics, Computers and Artificial Intelligence, Ploiesti, Romania, 2016.

[3] Prity Bisen and Amit Shrivastave, "Comparison between SVC and STATCOM FACTS Devices for Power System Stability Enhancement", International Journal on Emerging Technologies 4(20): 101109(2013).

[4] Jayant. P. Pawar, Amirthaganesh. S, ArunKumar. S and Satiesh Kumar. B, "Real Time Energy Measurement using Smart Meter", presented at Online Int. Conf. Green Engineering and Technologies(IC-GET), 2016.

[5] Shang-Wen Luan, Jen-Hao Teng, Shun-Yu Chan and Lian-Chyr Hwang, "Development of a Smart Meter for AMI based on ZigBee Communication", PEDS, 2009.

[6] Mustafa Burunkaya and Tufan Pars, "A Smart Meter Design and Implementation Using ZigBee Based
Wireless Sensor Network in Smart Grid", presented on $4^{\text {th }}$ Int. Conf. Electrical and Electronics Engineering, 2017.

[7] Khusvinder Gill, Shuang-Hua Yang, Fang Yao and Xin Lu, "A ZigBee-Based Home Automation System”, IEEE Trans. Consumer Electroncis, Vol 55, NO 2, MAY 2009.

[8] Hienz K. Tyll, SM, IEEE and Dr. Frank Schetter ${ }^{1}$, "Historical overview on dynamic reactive power compensation solutions from the begin of AC power transmission towards present applications", presented at IEEE/PES Systems Conference and Exposition. 2009.

[9] Mohamed Ali Khan, K.V.Satya Bharath, Sachin Mishra and Amit Kumar Singh, "Intelligent Cintrol of Fixed Capacitor-Thyristor Controlled Reacter for Power Quality Improvement”, 978-15090-4530-3/16. IEEE. 2016

[10] Alisha Banga and S.S. Kaushik, "Modelling and Simulation of SVC Controller for Enhancement of Power System Stability", presented at International Journal. Advances in Engineering \& Technology. 2011.

[11]Ali Kose and Edral Irmak, "Modelling and Simulation of a Static VAR Compensator based on FC-TCR", presented at Int. Conf. Renewable Energy Research and Application. Birmingham. UK. 2016.

[12] Yuval Beck, Yefim Berlovich and Arie Braunstein, "A Matlab-Simulink Model of AC Grid with a FCTCR and Invariant Control System for Reactive Power Compensation", presented at International symposium on Power Electronics, Electrical Drives, Automation and Motion. 2016.

[13] Swapnil Sharma and Dikesh Patel, "Modelling and Simulation of FC-TCR for Reactive Power Compensation using Matlab/Simulink", presented at International Journal. Advances in Engineering \& Technology, January, 2015.

[14] A. W. Abdul Ali, F. Asmida and A. R. Nasri Hayima, "A Review on The AC Servo Motor Control Systems", ELEKTRIKA- Journal of Electrical Engineering, vol. 19, no. 2, pp. 22-39, 2020.

[15]A. W. Abdul Ali and A. Alquhali, "Improved Internal Model Control Technique for Position Control of AC Servo Motors", ELEKTRIKA- Journal of Electrical Engineering, vol. 19, no. 1, pp. 33-40, 2020.

[16] Mohammad Hasanuzzaman Shawon, Zbigniew Hanzelka and Aleksander Dziadecki, "VoltageCurrent and Harmonic Characteristic Analysis of Different FC-TCR Based SVC" presented at Int. Conf. PowerTech. Eindhoven, Netherlands. July, 2015.

[17] Dang Van Huyen, Phan Than Nien and Nguyen Duy Cuong, "Design of Dynamic-Static Var Compensation based on Microcontroller for Improving Power Factor", presented at Int. Conf. System Science and Engineering (ICSSE). 2017.

[18] Taufik and Bryan Paet, "A Small Scale Static VAR Compensator for Laboratory Experiment”, presented 
at Int. Conf. Power and Energy. Johor Baharu, Malaysia. December, 2008.

[19] Sccott Zemerick, Powsiri Klinkhachorn and Ali Feliachi, "Design of a Mircroprocessor-Controlled Personal Static Var Compensator (PSVC)", presented at Int. Conf. Power Engineering Society Summer Meeting. Chicago, IL, USA, USA. September, 2002.

[20] S. Khanmohammadi, M. Tarafdar Hagh and M. Abapour, "Fuzzy Logic Based SVC for Reactive Power Compensation and Power Factor Correction", presented at Int. Conf. Power Engineering. Singapore, Singapore. December. 2007.
[21] Mr. Manan Y. Pathak and Dr. J. G. Jamnani, "Design and Hardware Implementation of SVC using Thyristorised Control for Improving Power Factor and Voltage Profile of Inductive Loads", presented at Int. Conf. Power Systems (ICPS). New Delhi, India. March. 2016.

[22] E. Acha, V. G. Agelidis, O. Anya-Lara and T.J.E Miller, "Power Electronics Control in Electrical Systems", $1^{\text {st }}$ ed. Newnes Power Engineering Series, 2000, pp. 152-372.

[23] T. Vijayakumar and A. Nirmalkumar, "Harmonics Analysis of Thyristor Controlled Reactor circuits", presented at Int. Journal. Computer and Electrical Engineering, Vol. 2, No. 1, February, 2010. 